\section{Estudo \\ cabebate}

em Testão

Planejamento
Revista Estudo \& Debate, Lajeado, v. 25, n. 2, 2018. ISSN 1983-036X

DOI: http://dx.doi.org/10.22410/issn.1983-036X.v25i2a2018.1632

\title{
TRABALHO, ESTUDO OU LAZER? UMA ABORDAGEM PROBABILÍSTICA PARA OS JOVENS DOS ESTADOS DA REGIÁO NORDESTE DO BRASIL
}

\author{
Helson Gomes de Souza ${ }^{1}$, Francisco José Silva Tabosa ${ }^{2}$
}

\begin{abstract}
Resumo: Este trabalho tem como objetivo identificar os fatores que determinam as escolhas dos jovens da região Nordeste do Brasil por trabalho, estudo ou lazer. Para tanto, utilizou-se uma metodologia probabilística multinomial, a fim de verificar a probabilidade de escolha ocupacional da populaçáo estudada, considerando os indivíduos com idade entre 16 e 29 anos e ainda os grupos de sexo. Concluiu-se que, para as mulheres da regiáo Nordeste, o perfil dos indivíduos que náo estudam nem trabalham é advindo da idade, do casamento e da idade de ingresso no mercado de trabalho. Em relaçáo aos homens, esse perfil é provindo da idade, da idade de ingresso no mercado de trabalho e da definiçáo de cor branca. Verificou-se, também, a necessidade de implantaçáo de medidas que visem inserir os jovens no mercado de trabalho.
\end{abstract}

Palavras-chave: Geração nem-nem. Jovens. Região Nordeste.

Classificaçáo JEL: O210, O40, O49

\section{WORK, STUDY OR LEISURE? A PROBABILISTIC APPROACH FOR YOUNG PEOPLE OF THE NORTHEAST REGIONS OF BRAZIL}

\begin{abstract}
This study aims to identify the factors that determine the choices of young people in the Northeast region of Brazil for work, study or leisure. For that, a multinomial probabilistic methodology was used in order to verify the probability of occupational choice of the studied population, considering the individuals between the ages of 16 and 29 years and the sex groups. It was concluded that, for the women of the Northeast region, the profile of the time that they do not study nor worker is coming of age, the marriage and the age of entry into the labor market. In relation to men, this profile is derived from the age, the age of entry into the labor market and the definition of white color. There was also a need to introduce measures to include young people in the labor market.
\end{abstract}

1 Graduado em Ciências Econômicas, aluno do Mestrado Acadêmico em Economia Rural da Universidade Federal do Ceará (MAER/UFC). Contato: helson.g.souza@gmail.com.

2 Doutor em economia pela Universidade Federal do Ceará, professor do departamento de economia agrícola da Universidade Federal do Ceará (DEA/MAER/UFC). Contato: franzetabosa@hotmail.com 
Keywords: Generation “nem-nem”. Young people. Northeastern Region.

JEL Classification: O210, O40, O49

\section{INTRODUÇÁO}

Dada uma série de características sociais, econômicas e culturais de uma determinada regiāo, os indivíduos podem apresentar preferências diferenciadas em relação às suas decisóes de ocupação. Nesse sentido, cada indivíduo pode possuir um conjunto de fatores que determinam as suas preferências e, consequentemente, suas escolhas de alocação de tempo. Sendo assim, fatores como a renda disponível ou experiência trabalhista podem determinar a escolha de um determinado indivíduo em, por exemplo, trabalhar ou não. As características educacionais também podem influenciar nas decisóes de estudo. Além disso, fatores estruturais ou característicos de determinada regiáo podem influenciar nas preferências relacionadas ao lazer (CORSEUIL; BOTELHO, 2014).

Dados do Instituto Brasileiro de Geografia e Estatística (IBGE) mostram que, no ano de 2015, 63,3\% dos jovens brasileiros com idade entre 10 e 25 anos optavam por se dedicarem exclusivamente ao estudo, enquanto apenas 6,6\% desses indivíduos optavam por conciliar trabalho e estudo. Além disso, o percentual de jovens brasileiros englobados na idade descrita que não estudavam e ao mesmo tempo não desempenhavam nenhuma função trabalhista nesse período foi de 3,6\% (IBGE, 2016).

Pessoas encaixadas nesse último critério compóem a chamada geração "nem-nem", descrita por Silva (2016) como um fato de ampla gravidade social e econômica, tendo em vista que esse conjunto de indivíduos engloba um considerável contingente de pessoas com idade apta ao trabalho e ao estudo, que estão, contudo, fora da escola e do mercado de trabalho.

Tillmann e Comin (2016) fizeram uma análise sobre as características que levam os jovens brasileiros a fazerem parte da geração "nem-nem" levando em consideração os grupos de sexo. Os resultados encontrados no estudo descrito indicaram diferentes consideraçóes entre os públicos analisados. Em geral, o estudo associou as mulheres da geração "nemnem" à baixa escolaridade, ao meio rural, ao casamento e à maternidade. Para os homens, os autores concluíram que fatores como o casamento e a cor do indivíduo reduzem as chances de escolha por permanência fora da escola e do mercado de trabalho.

$\mathrm{Na}$ região Nordeste do Brasil, destacada por possuir um status social e econômico mais vulnerável, se comparada às demais regiôes, os dados da Pesquisa Nacional por Amostra de Domicílios (PNAD), referente ao ano de 2014, mostram que dos jovens com idade entre 10 e 25 anos, $63,9 \%$ frequentam a escola, sendo que $6 \%$ conciliam trabalho e estudo. Já os jovens encaixados no perfil da geração "nem-nem" correspondem a 3,8\% da população, de maneira que, desses, 53,2\% são do sexo feminino.

Contanto, Alexandre e Menezes-Filho (2005) destacam que a disponibilidade de oportunidades tanto no mercado de trabalho quanto no sistema educacional interfere nos rendimentos trabalhistas e educacionais dos indivíduos. No que diz respeito às condiçóes ocupacionais referentes à educação, Mancebo, Vale e Martins (2015) afirmam que houve um crescimento recente da oferta de ensino em todas as regióes brasileiras, principalmente no 
que se refere ao ensino superior, entretanto, a demanda por vagas nesse nível de escolaridade ainda é superior à oferta. Além disso, Ferreira (2004) destaca que o retorno trabalhista de se possuir maiores níveis de escolaridade vem apresentando uma queda nos estados brasileiros no longo dos últimos anos. Com isso, pressupóe-se que esses fatores atuam como determinantes na situação ocupacional dos jovens.

Nesse sentido, estudos como os desenvolvidos por Camarano et al. (2012), Monteiro (2013) e Cardoso (2013) ressaltam a importância de pesquisas voltadas para a estimulação de incremento de políticas públicas que visem a inserção dos indivíduos "ociosos" no âmbito educacional ou no mercado de trabalho.

Tendo em vista essas consideraçóes, questiona-se sobre que fatores que levam uma parte dos jovens da regiáo Nordeste do Brasil a ficarem exclusos do trabalho e da escola. Com isso, o presente trabalho tem como objetivo identificar os fatores que determinam as escolhas dos jovens da região Nordeste do Brasil por não trabalhar nem estudar. Além disso, o trabalho objetiva indicar a probabilidade de cada possível escolha de ocupação levando em consideração o sexo dos jovens da região Nordeste do Brasil.

Ressalta-se que a contribuição passada pelo presente trabalho está fundamentada no estudo sobre as características ocupacionais dos jovens de uma região com características familiares "protecionistas", onde os jovens tendem a permanecer por mais tempo sob dependência dos seus genitores, assim como destacado no estudo de Ciríaco et al. (2015). Nesse sentido, a formulação de um estudo sobe as características ocupacionais dos jovens dessa regiấo forneceria mecanismos mais precisos para o planejamento e implantação de instrumentos que visem corrigir o viés ocupacional dos jovens que não estudam nem trabalham.

Esta pesquisa foi subdividida em cinco seçôes. A primeira referiu-se à parte introdutória da pesquisa. A segunda englobou o embasamento teórico e literário sob o qual o trabalho encontra-se fundamentado. A terceira abordou o arcabouço metodológico utilizado. Na quarta foram esboçados os resultados encontrados e as discussóes construídas com estudos sobre o tema estudado e, na quinta seção, foram apresentadas as conclusóes.

\section{REVISÃO DE LITERATURA}

Levando em consideração que os indivíduos agem de uma maneira racional, as decisóes de escolha tomadas em relação à alocação do tempo ocorrem de maneira a maximizar os níveis de satisfação, tendo em vista um conjunto de características referentes ao cotidiano desse indivíduo. Na perspectiva de Tillmann e Comin (2016), as decisóes de alocação de tempo dos jovens recebem interferência de fatores externos como família, renda e até perspectivas de ocasióes futuras.

As tomadas de decisão dos jovens envolvem fatores que não englobam apenas a escola ou o trabalho. O estudo desenvolvido por Camarano et al. (2012) demonstrou que o fator sexo pode interferir de diferentes maneiras nas escolhas ocupacionais dos jovens. Por exemplo, o fato de um indivíduo do sexo feminino não trabalhar nem estudar pode partir do princípio de que esse indivíduo tenha construído uma família e esteja desempenhando o tradicional papel de mãe e dona de casa. 
Gonzaga et al. (2012) elaboraram um estudo sobre a formação de aprendizes no mercado de trabalho brasileiro. Nele foi destacado que uma das grandes dificuldades dos jovens do país é determinar uma maneira que possa interligar a educação ao mercado de trabalho. Além disso, o estudo descrito destacou que as características socioeconômicas das famílias dos jovens interferem diretamente na escolha por trabalho ou estudo, uma vez que o ingresso do jovem no mercado de trabalho significa uma expansão da renda familiar, e sua permanência na escola contribui indiretamente para esse fator por meio do acúmulo de capital humano.

Cacciamali, Tatei e Batista (2010) determinaram que indivíduos pertencentes às populaçôes detentoras dos menores níveis de renda e/ou maiores níveis de pobreza possuem maiores incentivos a ingressarem precocemente no mercado de trabalho. Esse fato, na maioria das vezes, é proveniente da necessidade de complementação da renda familiar, que é insuficiente em grande parte dos casos. Em consequência desse fato, indivíduos com essa característica possuem dificuldades em ingressar em trabalhos com maiores remunerações, exercendo geralmente afazeres que necessitam de baixa qualificação profissional.

Em um estudo sobre a influência do background familiar na ocupação das crianças no estado do Pernambuco, Sobreira et al. (2016) concluíram que fatores como a cor e a situação censitária do indivíduo podem atuar como determinantes do fato de o jovem trabalhar, estudar ou não trabalhar nem estudar. Além disso, o referido estudo destacou que a renda familiar é um grande determinante nas decisóes ocupacionais dos jovens, de forma que crianças que apenas estudam são caracterizadas por apresentarem, em média, maiores níveis de renda.

Santos e Gimenez (2015) estudaram a inserção dos jovens no mercado de trabalho brasileiro. Para os autores, o fator renda familiar é um dos principais determinantes da escolha dos jovens brasileiros por trabalho ou estudo. Além disso, os autores destacaram que a piora do emprego e da renda das famílias num cenário de estreitamento das políticas públicas e da proteção social tende a impulsionar de forma mais intensa a procura de emprego por parte dos jovens brasileiros, levando na grande maioria dos casos a uma situação de abandono escolar.

Garcia et al. (2012) verificaram as condições de inserção dos jovens brasileiros no mercado de trabalho. $\mathrm{O}$ estudo destacou que os jovens apresentam dificuldades para ingressarem no mercado, sendo que, esse fato ocorre, geralmente, em decorrência das características socioeconômicas regionais, da baixa qualificação advinda de um aprendizado escolar debilitado e das exigências profissionais demandadas pelos empregadores. Destacaram ainda que a situação ocupacional dos jovens brasileiros é menos problemática em períodos de crescimento econômico, tendo em vista que, com o crescimento, há um favorecimento no ingresso desses indivíduos no mercado de trabalho.

Siqueira, Lima e Silva (2015) estudaram o efeito dos benefícios previdenciários sobre as escolhas por trabalho ou estudo nas regiōes brasileiras. No estudo descrito foi destacado que a presença de aposentadorias em um determinado município aumenta consideravelmente as chances de os jovens componentes desse domicílio estarem somente estudando. Por outro lado, indicaram que a presença apenas de pensionistas contribui 
para aumento da probabilidade de os jovens destes domicílios não estarem estudando ou trabalhando.

Gonçalves e Monte (2008) fizeram uma análise comparativa entre o volume de trabalhadores admitidos por primeiro emprego e os admitidos por reemprego no mercado formal de trabalho da regiáo Nordeste do Brasil. No estudo descrito, os autores destacaram que, nessa região, dentre os fatores que contribuem para que os jovens estejam fora do mercado de trabalho, destaca-se o baixo dinamismo econômico regional, a dificuldade de inserção ocupacional, devido à baixa qualidade de ensino e a falta de experiência ou habilidades exigidas pelas empresas na hora da contratação.

$\mathrm{Na}$ região Nordeste do Brasil, algumas evidências socioeconômicas interferem com maior intensidade nas escolhas dos indivíduos referentes a estudar ou trabalhar, criando uma concentração de pessoas, principalmente jovens, que não estão inseridos no mercado de trabalho, nem frequentam a escola. Além disso, destaca-se o fato de indivíduos englobados nesse contexto estarem geralmente inseridos em uma situação de pobreza. Nesse sentido, evidencia-se que fatores como as mudanças estruturais pelas quais o Brasil passou e as políticas públicas de redução de barreiras ao acesso à escola e ao mercado de trabalho reduziram o impacto das desigualdades regionais e aumentaram o peso da pobreza na explicação da condição “nem-nem” dos jovens (CARDOSO, 2013).

\subsection{A “geraçấo nem-nem”}

A literatura que aborda a camada social que se mantém fora do mercado de trabalho e também fora do âmbito educacional é bastante homogênea. O estudo desenvolvido por Camarano et al. (2012), por exemplo, buscou identificar os fatores que determinam a permanência de uma camada de indivíduos com idade compatível com a fase de estruturação educacional, sem trabalho e fora da escola. Já o estudo feito por Monteiro (2013) analisou o perfil dos jovens conhecidos como geração "nem-nem", no Brasil, durante a década de 2000. Dentre as conclusóes encontradas, demonstrou a autora que o número de jovens sem trabalho e fora da escola pouco variou durante os anos analisados em seu estudo.

$\mathrm{O}$ fato de os jovens optarem por não trabalhar nem estudar pode trazer graves consequências para o âmbito social. Em um estudo sobre essa camada social, na Europa, Robson (2008) concluiu que a escolha por permanecer fora da escola e do mercado de trabalho, faz com que esses indivíduos se submetam a uma alta probabilidade de ingressarem em atividades à margem da lei. Além disso, a autora ainda destacou que jovens encaixados nessa categoria geralmente são advindos de famílias com condiçóes socioeconômicas deficitárias, de forma que a estrutura social na qual esses jovens estão inseridos pode comprometer o desempenho escolar e gerar dificuldade de aprendizado, gerando, posteriormente, dificuldades referentes ao ingresso no mercado de trabalho.

Reis e Camargo (2007) analisaram o papel das aposentadorias e pensóes nas decisóes sobre trabalho, estudo, ou não trabalhar nem estudar, em relação aos jovens brasileiros. $\mathrm{O}$ referido estudo demonstrou que a presença de aposentados e pensionistas no domicílio pode levar a uma maior probabilidade de os jovens dedicarem-se exclusivamente ao estudo, 
entretanto, concluíram que a presença de rendimentos advindos de pensões e aposentadorias pode levar à existência de jovens que não trabalham nem estudam.

De acordo com Camarano et al. (2006) a maioria dos jovens brasileiros que não possui trabalho e estáo fora da escola é composta por indivíduos do sexo feminino, que se declaram de cor parda. Monteiro (2013) também destacou que a maioria dos jovens conhecidos como "nem-nem" são do sexo feminino, sendo que a maior parte desse público é composta por mulheres que possuem filhos, embora o número de jovens mães, sem emprego e fora da escola, esteja reduzindo durante os anos da década de 2000.

O estudo construído por Tillmann e Comin (2016) indicou que, no Brasil, os indivíduos que se dedicam exclusivamente ao estudo são aqueles que possuem entre cinco e dez anos de escolaridade, enquanto a categoria de jovens que possuem dedicaçáo exclusiva ao trabalho é representada, em sua grande maioria, por indivíduos que possuem entre onze e quatorze anos de escolaridade, ou seja, teoricamente, possuem o nível médio completo. Nesse sentido, é notável que o nível de escolaridade dos jovens possui interferência direta sobre suas escolhas por trabalho ou estudo.

Vasconcelos et al. (2016) indicaram que existe a necessidade de implantação de políticas públicas que visem reduzir a quantidade de jovens considerados "nem-nem" no Brasil. No referido estudo é destacado que medidas como os programas de transferência direta de renda reduzem a probabilidade de os jovens se enquadrarem nesse perfil. Os autores ainda mencionaram que os programas de transferência de renda proporcionam maiores condiçóes para que os jovens frequentem a escola, facilitando o seu posterior ingresso no mercado de trabalho.

Os fatores determinantes da alocação do tempo dos jovens da América Latina foram estudados por Menezes Filho, Cabanas e Komatsu (2002). No referido estudo foi demonstrado que o nível educacional dos pais é um fator importante para a decisão de escolha do jovem. Além disso, concluíram que os níveis de renda familiar incidem diretamente sobre as decisóes de alocação do tempo dos jovens da regiáo descrita.

Para Tillmann e Comin (2016), um dos principais fatores que fazem com que o Brasil possua um grande contingente de jovens que têm aptidão trabalhista, mas não estão trabalhando é a dificuldade de inserção desses jovens no mercado. Isto é geralmente ocasionado pela alta volatilidade do mercado de trabalho nessa faixa etária, além da dificuldade de integração e identificaçáo própria com as atividades a eles dispostas.

A questão do trabalho durante a infância foi abordada no estudo de Cardozo e Souza (2004), que verificaram os impactos dos programas de transferência de renda sobre o trabalho infantil e o desempenho escolar dos jovens. Concluíram no seu estudo que os programas de transferência de renda não possuem impactos significativos sobre o trabalho infantil, entretanto, esses programas possuem impactos sobre a presença das crianças na escola e no seu respectivo desempenho escolar.

O nível de escolaridade pode ser um determinante das escolhas de alocação de tempo dos jovens, também quando analisado em detrimento dos componentes familiares. $\mathrm{O}$ estudo de Kassouf (2002) fez uma análise probabilística sobre as chances de crianças trabalharem e estudarem, levando em consideração as áreas urbanas e rurais do Brasil. No referido estudo 
foi constatado que, em famílias em que os pais possuem maiores níveis de escolaridade, a probabilidade de as crianças trabalharem é reduzida, em consequência, a probabilidade de as crianças dedicarem-se exclusivamente ao estudo aumenta.

De acordo com Tillmann e Comin (2016), entre as mulheres, fatores como a maternidade e o casamento atuam como fatores determinantes nas decisóes sobre trabalho e estudo. Os autores indicaram que esses fatores elevam a probabilidade de as jovens do sexo feminino optarem por não trabalhar nem estudar.

Para Monteiro (2013), em relação à educação, fatores como a dificuldade de acesso ao ensino superior levam os jovens brasileiros a uma situação de ociosidade. Já em relação ao mercado de trabalho, concluiu a autora que o problema principal enfrentado pelos jovens brasileiros não é a dificuldade em conseguir um trabalho, e sim permanecer nele.

\section{METODOLOGIA}

Essa seção destina-se a apresentar os instrumentos utilizados para buscar uma resposta para o problema aqui abordado. Serão expostos os métodos a serem utilizados, bem como o tratamento auferido aos dados em questão.

\subsection{Modelo de escolha multinomial}

Tendo em vista que os indivíduos estudados estão expostos a uma escolha multicategórica, a probabilidade de ocorrência da escolha de uma determinada categoria é dada por Greene (2008) por meio de um modelo de escolha multinomial. Nesse tipo de abordagem, o $i$-ésimo indivíduo é confrontado com as utilidades de $j$, a qual é dada por:

$$
U_{i j}=z_{i j}^{\prime} \theta+\varepsilon_{i j}
$$

Caso o indivíduo opte pela escolha $j$, então se considera que $U_{i j} U_{i j}$ assume valor máximo entre as utilidades de $j$. Nesse sentido, Greene (2008) indica que o modelo probabilístico multinomial é baseado na probabilidade de o indivíduo escolher $j$, sendo

$$
\operatorname{Prob}\left(U_{i j}>U_{i k}\right) \forall k \neq j \operatorname{Prob}\left(U_{i j}>U_{i k}\right) \forall k \neq j \text {. }
$$

Greene (2008) destaca que no modelo logit multinomial, para um tomador de decisóes com características $w_{i} w_{i}$, as equaçóes estimadas fornecem um conjunto de probabilidades para as $j+1 j+1$. Com isso tem-se:

$$
\operatorname{Prob}\left(Y_{i}=j \mid w_{i}\right)=P_{i j}=\frac{\exp \left(w_{i}^{\prime} \alpha_{j}\right)}{1+\sum_{k=1}^{j} \exp \left(w_{i}^{\prime} \alpha_{j}\right)} \quad \operatorname{com} \mathrm{j}=0,1, \ldots, \mathrm{J} \text { e } \alpha_{0}=0
$$

O impacto de $w_{i} w_{i}$ sobre a possibilidade de escolha de $j$ pode ser analisada por meio do logaritmo da razão de probabilidades (log-odds ratio) ${ }^{3}$, que fornece uma taxa de risco relativa em detrimento de uma determinada escolha, sendo dada por Greene (2008) como:

3 Nesse caso considera-se que $P_{i j} / P_{i k} P_{i j} / P_{i k}$ não depende de outras escolhas. 
$\ln \left[\frac{P_{i j}}{P_{i k}}\right]=w_{i}^{\prime}\left(\alpha_{j}-\alpha_{k}\right)=w_{i}^{\prime} \alpha_{j} \quad$ se $k=0$

Ou por meio dos efeitos marginais, dados por:

$$
\delta_{i j}=\frac{\partial P_{i j}}{\partial w_{i}}=P_{i j}\left[\alpha_{j}-\sum_{k=0}^{j} P_{i k} \alpha_{k}\right]=P_{i j}\left[\alpha_{j}-\bar{\alpha}\right]
$$

As estimações do modelo logit multinomial serão feitas seguindo o procedimento indicado por Camarano et al. (2012) e utilizado por Tillmann e Comin (2016), onde é demonstrado que as escolhas ocupacionais variam em relação ao sexo do indivíduo. Assim, serão feitas três estimações, sendo a primeira, referente à amostra completa, englobando ambos os sexos; a segunda referente aos indivíduos do sexo masculino e; a terceira relacionada às jovens do sexo feminino.

\subsection{Base de dados}

Os dados utilizados foram extraídos da Pesquisa Nacional por Amostra de Domicílios (PNAD), disponibilizada anualmente pelo Instituto Brasileiro de Geografia e Estatística (IBGE). Para a construção do presente trabalho utilizou-se a PNAD referente aos anos de 2011, 2012, 2013 e 2014. A escolha do referido período é dada pelo fato de esse representar a introdução de uma mudança governamental inserida no Brasil após o final da década de 2000 .

A área estudada no presente trabalho corresponde aos nove estados da Região Nordeste do Brasil. As variáveis utilizadas e suas respectivas especificaçôes estão disponibilizadas no Quadro 1.

Quadro 1 - Descrição das variáveis utilizadas

\begin{tabular}{|c|c|}
\hline Variável & Descrição \\
\hline$Y$ & $\begin{array}{l}\text { Variável escolha }=(0 \text { se o indivíduo apenas trabalhou no período de referência; } \\
1 \text { se o indivíduo apenas estudou no período de referência; } 2 \text { se o indivíduo } \\
\text { trabalhava e frequentava a escola no período de referência e } 3 \text { se o indivíduo náo } \\
\text { trabalhava e nem frequentava a escola no período de referência). }\end{array}$ \\
\hline Rend_c & Renda do chefe da família. \\
\hline Esc & Anos de estudo do indivíduo. \\
\hline$E s c_{-} c$ & Escolaridade do chefe da família. \\
\hline Idade & Idade do indivíduo. \\
\hline Est_civ & $\begin{array}{c}\text { Variável binária }=(0 \text { se o indivíduo náo vive em companhia de cônjuge ou } \\
\text { companheiro e } 1 \text { caso contrário). }\end{array}$ \\
\hline Cor & $\begin{array}{c}\text { Variável binária = (0 se o indivíduo é declarado de cor náo branca e } 1 \text { caso } \\
\text { contrário). }\end{array}$ \\
\hline Sexo & $\begin{array}{c}\text { Variável binária }=(0 \text { se o indivíduo é do sexo feminino e } 1 \text { se é do sexo } \\
\text { masculino }) .\end{array}$ \\
\hline
\end{tabular}




\begin{tabular}{|c|c|}
\hline Variável & Descrição \\
\hline Filho & $\begin{array}{c}\text { Variável binária }=(0 \text { se o indivíduo do sexo feminino não teve filho nascido vivo } \\
\text { no período de referência da pesquisa e 1 caso contrário })\end{array}$ \\
\hline Urbano & $\begin{array}{c}\text { Variável binária }=(0 \text { se o indivíduo reside no meio rural e 1 se o indivíduo reside } \\
\text { no meio urbano }) .\end{array}$ \\
\hline Comp & Número de componentes do domicílio. \\
\hline
\end{tabular}

Fonte: Elaboração dos autores.

Usando as decisões de trabalho como base categórica do modelo, as estimações posteriores poderão indicar sob que condiçôes os indivíduos preferem trabalho, estudo ou lazer. Para esse procedimento, utilizaram-se as observaçóes referentes aos indivíduos com idade entre 16 e 29 anos. A idade mínima de 16 anos foi escolhida por representar a aptidáo ao trabalho de acordo com as especificaçóes do Ministério do Trabalho. Já a idade máxima de 29 anos foi escolhida com base em estudos anteriores sobre o tema como nos estudos de Silva (2016) e Tillmann e Comin (2016). Ambos os trabalhos delimitam esse valor com base na Emenda à Constituição no 42/2008, a qual institui que a idade máxima para que $o$ indivíduo seja considerado como jovem é de 29 anos.

O direcionamento do estudo para com a região Nordeste do Brasil dá-se em função do caráter familiar protecionista inserido nessa região. Esse fato é avaliado, por exemplo, no estudo de Ciríaco et al. (2015), onde é destacado que os jovens da região Nordeste possuem uma tendência de permanência no ambiente familiar de origem. Além disso, a opçáo de estudo pela região Nordeste do Brasil dá-se também em decorrência das suas características socioeconômicas particulares, as quais podem interferir nas escolhas ocupacionais dos jovens.

As estatísticas descritivas das variáveis utilizadas encontram-se dispostas na Tabela 1. Considerando a média dos dados, observa-se que, em relação à amostra completa durante o período estudado, a maioria dos indivíduos englobados na amostra é do sexo masculino, de cor não branca, solteiros e residentes no meio urbano. Além disso, observa-se que, em média, os indivíduos estudados possuem o ensino fundamental completo com níveis de escolaridade superior aos chefes dos domicílios. Verifica-se, também, que, em média, os indivíduos do sexo feminino possuem maiores níveis de escolaridade e são mais velhos, se comparado aos jovens do sexo masculino. Além disso, nota-se que, em média, as mulheres da região estudada concentram-se em uma maior proporção do que os homens no meio urbano. 
Tabela 1 - Estatísticas descritivas das variáveis

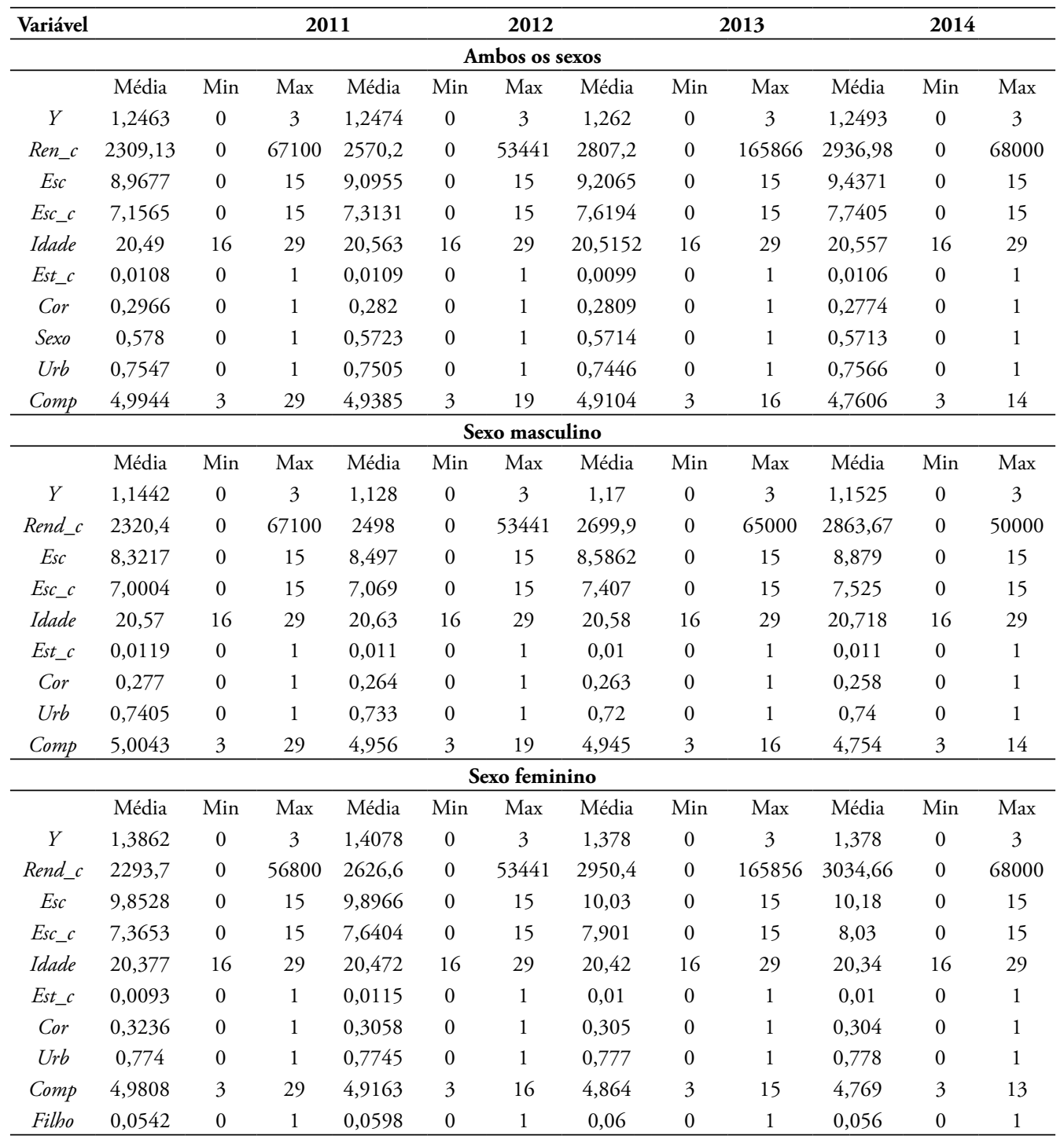

Fonte: Elaboração dos autores.

Após a homogeneização dos dados, as amostras utilizadas obtiveram características distintas a depender do ano abordado. Para 2011, foram utilizadas 8401 observaçóes, sendo 3545 indivíduos do sexo feminino e 4856 do sexo masculino. No ano de 2012, a amostra totalizou 8524 observaçóes, sendo 3646 indivíduos do sexo feminino e 4878 do sexo masculino. Em 2013, a amostra conteve 8014 observaçóes com 3435 indivíduos do sexo feminino e 4579 do sexo masculino. Para 2014, a amostra totalizou 8011 observaçóes, de maneira que, 3434 foram referentes aos indivíduos do sexo feminino e 4577 do sexo masculino. 


\section{RESULTADOS E DISCUSSÃO}

Nessa sessão são esboçados os resultados obtidos com os efeitos marginais do modelo logit multinomial, de acordo com o sexo dos indivíduos, seguindo o procedimento indicado por Camarano et al. (2012) e utilizado por Tillmann e Comin (2016). Os resultados das estimaçôes estão dispostos em apêndice, enquanto os efeitos marginais dessas estimações são apresentados e discutidos ao longo dessa seçáo.

Visando obter as probabilidades de escolha ocupacional dos jovens da região Nordeste, de uma maneira geral, estimou-se o modelo logit multinomial englobando indivíduos de ambos os sexos em uma única amostra. Os resultados para esse procedimento estão demonstrados na Tabela 2, por meio do cálculo dos efeitos marginais referentes à estimação, disposta na Tabela 5.

Os resultados demonstram que elevaçóes na renda do chefe do domicílio elevam as probabilidades de escolha dos jovens da região estudada nas três primeiras categorias. Além disso, o aumento dessa variável atua como redutor das chances de escolha dos jovens por um perfil "nem-nem".

Assim como verificado nos estudos de Vieira et al. (2016) e Tillmann e Comin (2016) observa-se que os jovens com maiores níveis de escolaridade estão mais propensos a escolherem alocar seu tempo com estudo ou com a conciliação de trabalho com estudo. Além disso, verifica-se que esses indivíduos estão menos propensos a não trabalhar nem estudar. Em tese, indivíduos mais qualificados possuem maior atratividade no mercado de trabalho, além de compreenderem a importância da qualificaçáo educacional.

Os resultados obtidos com a variável escolaridade do chefe indicam que indivíduos pertencentes a famílias com chefes com maiores níveis educacionais possuem menores probabilidades de optarem por apenas trabalhar, além de estarem mais propensos a optarem pelo estudo. Em relação à categoria que indica os jovens que não trabalham nem estudam, o último ano analisado obteve significância estatística e sinal positivo, demonstrando que elevações no nível de escolaridade do chefe da família elevam a probabilidade de escolha do jovem por um perfil "nem-nem". Ciríaco et al. (2015) demonstraram que se tornou bastante comum que jovens de idade adulta residirem com seus pais e apresentarem uma situação de dependência. Além disso, Tillmann e Comin (2016) observaram esse mesmo resultado, quando subdividiram os indivíduos brasileiros por sexo por meio de dados da PNAD, referentes ao ano de 2011.

Verifica-se também que indivíduos casados ou mais velhos estão mais propensos a escolherem o trabalho ou o lazer, além de possuírem menores probabilidades de optarem pelo estudo ou por trabalhar e estudar. Esses resultados corroboram com as análises feitas nos estudos de Vieira et al. (2016) e Costa e Ulyssea (2014).

Em relação à cor do indivíduo, nos anos em que a referida variável apresentou significância estatística, nota-se que os indivíduos de cor branca estáo menos propensos a escolherem apenas o trabalho e mais propensos a optarem por apenas estudar, assim como demonstrado no estudo de Camarano et al. (2012).

Verifica-se que o meio urbano é responsável por aumentar a probabilidade de escolha dos jovens da regiáo Nordeste pelo estudo e pelo lazer, reduzindo as probabilidades de 
escolha pela categoria trabalho e estudo. Além disso, observa-se que jovens residentes em domicílios com mais pessoas possuem maior propensão a escolherem apenas trabalhar ou trabalhar e estudar.

Os resultados obtidos com o variável sexo confirmam o que é demonstrado na literatura voltada para as decisóes ocupacionais dos jovens. De uma forma geral, os jovens do sexo masculino da regiáo Nordeste estão mais aptos a escolherem alocar seu tempo com trabalho e com a conciliação de trabalho e estudo. Por outro lado, o fato de o jovem pertencer ao sexo masculino reduz a probabilidade de escolha ocupacional pelo estudo e pelo lazer. Outras pesquisas ligadas à geração "nem-nem" também obtiveram resultados semelhantes, como é o caso dos estudos formulados por Vieira et al. (2016), Costa e Ulyssea (2014) Camarano et al. (2012) e Tillmann e Comin (2016).

Tabela 2 - Efeitos marginais do modelo logit multinomial para ambos os sexos

\begin{tabular}{|c|c|c|c|c|}
\hline & 2011 & 2012 & 2013 & 2014 \\
\hline \multicolumn{5}{|c|}{ Trabalho } \\
\hline Rend_c & 0,000002 & $0,000008^{* * *}$ & $0,000003^{*}$ & $0,0000^{* * *}$ \\
\hline Esc & $-0,00002$ & 0,0024 & $-0,0012$ & $-0,0003$ \\
\hline$E s c_{-} c$ & $-0,0124^{* * *}$ & $-0,0167^{* * *}$ & $-0,0119^{* * *}$ & $-0,0135^{* * *}$ \\
\hline Idade & $0,0648^{* * *}$ & $0,0624^{* * *}$ & $0,0624^{* * *}$ & $0,0647^{* * *}$ \\
\hline Est_c & $0,1517^{* *}$ & $0,1615^{* * *}$ & $0,2452^{* * *}$ & 0,0792 \\
\hline Cor & $-0,0154$ & $-0,028^{* *}$ & 0,0068 & $-0,034^{* *}$ \\
\hline$U r b$ & $-0,0339^{* *}$ & $-0,0124$ & $-0,002$ & $-0,0445^{* * *}$ \\
\hline Comp & $0,0074^{* *}$ & 0,0027 & $0,0094^{* * *}$ & 0,0054 \\
\hline Sexo & $0,1868^{* * *}$ & $0,1844^{* * *}$ & $0,1764^{* * *}$ & $0,1669^{* * *}$ \\
\hline \multicolumn{5}{|c|}{ Estudo } \\
\hline Rend_c & $0,00001^{* * *}$ & $0,000004^{* *}$ & $0,000006^{* * *}$ & $0,00001^{* * *}$ \\
\hline Esc & 0,0005 & $0,004^{*}$ & $0,0078^{* * *}$ & $0,0048^{* *}$ \\
\hline$E s c_{-} c$ & $0,0116^{* * *}$ & $0,0143^{* * *}$ & $0,0116^{* * *}$ & $0,0121^{* * *}$ \\
\hline Idade & $-0,082^{* * *}$ & $-0,0771^{* * *}$ & $-0,0817^{* * *}$ & $-0,0823^{* * *}$ \\
\hline Est_c & $-0,1857^{* *}$ & $-0,1694^{* *}$ & $-0,4445^{* * *}$ & $-0,2396^{* * *}$ \\
\hline Cor & $0,0429^{* * *}$ & 0,016 & $0,0249^{* *}$ & $0,0281^{* *}$ \\
\hline$U r b$ & $0,0735^{* * *}$ & $0,0226^{*}$ & $0,0251^{*}$ & $0,0395^{* *}$ \\
\hline Comp & $-0,006^{* *}$ & $-0,016^{* * *}$ & $-0,0095^{* * *}$ & $-0,0127^{* * *}$ \\
\hline Sexo & $-0,1351^{* * *}$ & $-0,0979^{* * *}$ & $-0,1278^{* * *}$ & $-0,1121^{* * *}$ \\
\hline \multicolumn{5}{|c|}{ Trabalho e estudo } \\
\hline Rend_c & $0,000009^{* * *}$ & $0,00008^{* * *}$ & $0,00005^{* * *}$ & $0,00008^{* * *}$ \\
\hline Esc & $0,0173^{* * *}$ & $0,0169^{* * *}$ & $0,016^{* * *}$ & $0,0158^{* * *}$ \\
\hline$E s c_{-} c$ & $-0,0008$ & 0,0006 & $-0,0016$ & $-0,001$ \\
\hline Idade & $-0,0131^{* * *}$ & $-0,0165^{* * *}$ & $-0,0129^{* * *}$ & $-0,013^{* * *}$ \\
\hline Est_c & $-0,1343^{* *}$ & $-0,0989$ & 0,0732 & 0,0567 \\
\hline Cor & $-0,0227^{* *}$ & $-0,0135$ & $-0,0169$ & 0,0022 \\
\hline Urb & $-0,0921^{* * *}$ & $-0,0517^{* * *}$ & $-0,0487^{* * *}$ & $-0,0152$ \\
\hline Comp & 0,0001 & $0,0093^{* * *}$ & 0,003 & 0,004 \\
\hline Sexo & $0,0418^{* * *}$ & $0,0333^{* * *}$ & $0,0303^{* * *}$ & $0,0351^{* * *}$ \\
\hline \multicolumn{5}{|c|}{ Nem-nem } \\
\hline Rend_c & $-0,00002^{s}$ & $-0,00002^{s}$ & $-0,00002^{s}$ & $-0,00003^{s}$ \\
\hline Esc & $-0,0178^{* * *}$ & $-0,0232^{* * *}$ & $-0,2226^{* * *}$ & $-0,0203^{* * *}$ \\
\hline
\end{tabular}




\begin{tabular}{ccccc}
\hline & $\mathbf{2 0 1 1}$ & $\mathbf{2 0 1 2}$ & $\mathbf{2 0 1 3}$ & $\mathbf{2 0 1 4}$ \\
\hline Esc_c & 0,0016 & $0,0018^{*}$ & $-0,002$ & $0,0024^{*}$ \\
Idade & $-0,0303^{s}$ & $-0,0312^{s}$ & $-0,0322^{s}$ & $-0,0307^{s}$ \\
Est_c & $0,1683^{* * *}$ & $0,1068^{* *}$ & $0,1271^{* *}$ & $0,1037^{* *}$ \\
Cor & $-0,0047$ & $0,0254^{* *}$ & $-0,0148$ & 0,0038 \\
Urb & $0,0525^{* * *}$ & $0,0416^{* * *}$ & $0,0255^{* *}$ & 0,0202 \\
Comp & $-0,0016$ & 0,0041 & $-0,0028$ & 0,0033 \\
Sexo & $-0,0935^{s}$ & $-0,1198^{s}$ & $-0,0789^{s}$ & $-0,0899^{s}$ \\
\hline
\end{tabular}

Fonte: Elaboração dos autores.

Nota: Valores sucedidos dos símbolos $\left({ }^{* *}\right),\left({ }^{* *}\right)$ e $\left(^{*}\right)$ indicam significância estatística a nível de $1 \%, 5 \%$ e $10 \%$ de confiabilidade respectivamente. Valores sucedidos de " $\mathrm{s}$ " indicam significância estatística a 5\% de confiabilidade e relevância de acordo com a literatura econômica.

Os estudos de Camarano et al. (2012) e Sobreira et al. (2016) identificam diferentes perspectivas sobre as escolhas ocupacionais dos jovens, a depender do sexo do indivíduo. Buscando verificar esse contexto, a abordagem econométrica utilizada é feita levando em consideração as informaçóes do sexo dos jovens estudados.

$\mathrm{Na}$ Tabela 3 estáo expostos os efeitos marginais do modelo logit multinomial disposto na Tabela 5, referentes às estimaçóes que consideram apenas os indivíduos do sexo masculino.

Tabela 3 - Efeitos marginais do modelo logit multinomial para os jovens do sexo masculino

\begin{tabular}{|c|c|c|c|c|}
\hline & 2011 & 2012 & 2013 & 2014 \\
\hline \multicolumn{5}{|c|}{ Trabalho } \\
\hline Rend_c & 0,000002 & 0,000004 & $0,000005^{* *}$ & $0,00002^{* * *}$ \\
\hline Esc & $-0,0091^{* * *}$ & $-0,0055^{* *}$ & $-0,0095^{* * *}$ & $-0,0078^{* *}$ \\
\hline$E s c_{-} c$ & $-0,0138^{* * *}$ & $-0,0185^{* * *}$ & $-0,0146^{* * *}$ & $-0,014^{* * *}$ \\
\hline Idade & $0,0747^{* * *}$ & $0,0734^{* * *}$ & $0,0696^{* * *}$ & $0,0727^{* * *}$ \\
\hline Est_c & $0,1885^{* *}$ & $0,2282^{* * *}$ & $0,3221^{* * *}$ & $0,1976^{* *}$ \\
\hline Cor & $-0,0206$ & $-0,0289$ & $0,0357^{* *}$ & $-0,073^{* *}$ \\
\hline Urb & $-0,0908^{* * *}$ & $-0,0421^{* *}$ & $-0,037^{*}$ & $-0,0817^{* * *}$ \\
\hline Comp & $0,0096^{* *}$ & 0,0036 & $0,0133^{* * *}$ & 0,0027 \\
\hline \multicolumn{5}{|c|}{ Estudo } \\
\hline Rend_c & $0,000006^{* *}$ & $-0,000003$ & $0,00001^{* * *}$ & $0,000008^{* * *}$ \\
\hline Esc & $0,0101^{* * *}$ & $0,0107^{* * *}$ & $0,0126^{* * *}$ & $0,0099^{* * *}$ \\
\hline$E s c_{-} c$ & $0,0098^{* * *}$ & $0,0105^{* * *}$ & $0,0102^{* * *}$ & $0,0097^{* * *}$ \\
\hline Idade & $-0,0712^{* * *}$ & $-0,0688^{* * *}$ & $-0,0724^{* * *}$ & $-0,0718^{* * *}$ \\
\hline Est_c & $-0,0768$ & $-0,1576^{*}$ & $-0,306^{*}$ & $-0,3924^{* *}$ \\
\hline Cor & $0,0295^{* *}$ & $0,0276^{* *}$ & 0,009 & $0,0251^{*}$ \\
\hline Urb & $0,1027^{* * *}$ & $0,0733^{* * *}$ & $0,0426^{* *}$ & $0,056^{* * *}$ \\
\hline $\operatorname{Comp}$ & $-0,0076^{* *}$ & $-0,0133^{* * *}$ & $-0,0119^{* * *}$ & $-0,0082^{* *}$ \\
\hline \multicolumn{5}{|c|}{ Trabalho e estudo } \\
\hline Rend_c & $0,000009^{* * *}$ & $0,000007^{* * *}$ & $0,00001^{* * *}$ & $0,000007^{* * *}$ \\
\hline$E s c$ & $0,0175^{* * *}$ & $0,0186^{* * *}$ & $0,0172^{* * *}$ & $0,0162^{* * *}$ \\
\hline$E s c_{-} c$ & 0,00003 & 0,0022 & 0,0007 & 0,0013 \\
\hline Idade & $-0,027^{* * *}$ & $-0,0283^{* * *}$ & $-0,0242^{* * *}$ & $-0,0257^{* * *}$ \\
\hline Est_c & $-0,1998^{*}$ & $-0,012$ & 0,046 & 0,1019 \\
\hline Cor & $-0,0071$ & $-0,0134$ & $-0,0202$ & 0,0046 \\
\hline
\end{tabular}




\begin{tabular}{ccccc}
\hline & $\mathbf{2 0 1 1}$ & $\mathbf{2 0 1 2}$ & $\mathbf{2 0 1 3}$ & $\mathbf{2 0 1 4}$ \\
\hline Urb & $-0,1072^{* * *}$ & $-0,085^{* * *}$ & $-0,0682^{* * *}$ & $-0,0463^{* * *}$ \\
Comp & 0,0006 & $0,0082^{* *}$ & $0,0076^{* *}$ & $0,0065^{*}$ \\
\hline Rend_c & Nem-nem & $-0,00003^{s}$ \\
Esc & $-0,00002^{s}$ & $-0,00001^{s}$ & $-0,00002^{s}$ & $-0,0183^{* * *}$ \\
Esc_c & $-0,0184^{* * *}$ & $-0,0238^{* * *}$ & $-0,0202^{* * *}$ & $0,003^{*}$ \\
Idade & $-0,0041^{s}$ & $-0,0057^{s}$ & $-0,0052^{s}$ & $-0,0248^{s}$ \\
Est_c & $-0,0235^{s}$ & $-0,0237^{s}$ & $-0,027^{s}$ & 0,0929 \\
Cor & 0,0881 & $-0,0586$ & $-0,0621$ & 0,0076 \\
Urb & $-0,0019$ & 0,0147 & $-0,0245$ & $0,072^{* * *}$ \\
Comp & $0,0953^{* * *}$ & $0,0539^{* * *}$ & $0,0626^{* * *}$ & $-0,0009$ \\
\hline
\end{tabular}

Fonte: Elaboração dos autores.

Nota: Valores sucedidos dos símbolos $\left({ }^{* *}\right),\left({ }^{* *}\right)$ e $\left(^{*}\right)$ indicam significância estatística a nível de $1 \%$, 5\% e $10 \%$ de confiabilidade respectivamente. Valores sucedidos de " $\mathrm{s}$ " indicam significância estatística a 5\% de confiabilidade e relevância de acordo com a literatura econômica.

A partir dos resultados obtidos é possível afirmar que, nos anos em que obteve significância estatística, a variável renda do chefe da família obteve sinal positivo nas categorias trabalho, estudo e trabalho e estudo, o que indica que elevaçóes na renda do chefe da família aumentam a probabilidade de o indivíduo optar pelo trabalho, estudo ou pela conciliação dessas duas categorias ocupacionais. Em relação à categoria que indica a possibilidade de não trabalhar nem estudar, a referida variável obteve sinal negativo e significância estatística para todos os períodos analisados, determinando que a elevação na renda do chefe da família reduz a probabilidade de escolha do indivíduo pelo lazer.

Os resultados obtidos com a variável escolaridade demonstraram que indivíduos com maiores níveis de escolaridade estão mais propensos a optarem pelo estudo ou pela conciliação do trabalho e do estudo. Por outro lado, os indivíduos com mais anos de estudo possuem menores probabilidades de optarem apenas pelo trabalho ou pela ociosidade. Esse resultado corrobora com as afirmaçóes feitas no estudo de Monteiro (2013), onde é constatado que os jovens que constituem a geração "nem-nem" caracterizam-se por possuírem baixos níveis de escolaridade.

A literatura voltada para o estudo dos jovens "nem-nem", considera as características educacionais dos chefes da família como fator determinante das escolhas ocupacionais dos filhos, como é o caso dos estudos de Sobreira et al. (2016) e Tillmann e Comin (2016). No presente trabalho considerou-se a quantidade de anos de estudo como componente educacional do chefe familiar. Os resultados demonstram que, para os homens, o aumento na escolaridade do chefe da família irá reduzir a probabilidade de escolha pelo trabalho e aumentará as probabilidades de escolha pelo estudo e pelo lazer.

Tillmann e Comin (2016) indicaram que a idade é um fator determinante nas escolhas ocupacionais dos indivíduos brasileiros. Em suma, os resultados obtidos para a região estudada apontaram que os jovens do sexo masculino e com maior idade estão mais propensos a apenas trabalhar ou não trabalhar nem estudar. Já os homens mais jovens possuem maiores probabilidades de escolherem apenas estudar ou conciliarem trabalho e estudo, corroborando com os resultados encontrados por Tillmann e Comin (2016). 
A situação conjugal dos jovens do sexo masculino da região Nordeste mostra que os indivíduos casados possuem maior probabilidade de optarem por apenas trabalhar e menores probabilidades pela escolha do estudo. Em tese, o casamento demanda afazeres trabalhistas que acabam por reduzir o tempo no qual os homens dedicar-se-iam às atividades escolares, justificando, assim, o sinal obtido na categoria estudo.

Em relação à cor do indivíduo, observa-se que homens de cor branca estão menos propensos à escolha de apenas trabalhar e possuem maiores probabilidades de optarem por estudar, assim como observado no estudo de Vieira et al. (2016). Já em relação à situação censitária, observa-se que os homens do meio urbano possuem menor probabilidade de apenas trabalhar ou de conciliar trabalho com estudo. Além disso, verifica-se que esses indivíduos estão mais propensos a apenas estudar e possuem maior probabilidade de optar pelo lazer.

Nos anos em que obteve significância estatística, a variável que indica o número de componentes do domicílio demonstra que, para os indivíduos do sexo masculino, a elevação da quantidade de pessoas residentes no domicílio aumenta a probabilidade de escolha pelo trabalho e pela conciliaçáo de trabalho com estudo. Além disso, aumentos nessa variável reduzem as probabilidades de escolha do indivíduo por estudo e lazer.

A Tabela 4 apresenta os resultados dos efeitos marginais para as estimaçóes referentes aos indivíduos do sexo feminino, apresentadas na Tabela 7. Seguindo a indicaçáo de Camarano et al. (2012), os quais determinam que fatores como a maternidade podem interferir nas escolhas ocupacionais dos jovens do sexo feminino, por meio da dedicação aos afazeres familiares e domésticos. As estimaçóes feitas para esse público englobam também o fato de a mulher ter ou não possuído filhos até o período de referência.

Tabela 4 - Efeitos marginais do modelo logit multinomial para os jovens do sexo feminino

\begin{tabular}{ccccc}
\hline & $\mathbf{2 0 1 1}$ & $\mathbf{2 0 1 2}$ & $\mathbf{2 0 1 3}$ & $\mathbf{2 0 1 4}$ \\
\hline Rend_c & Trabalho & $0,000009^{* * *}$ \\
Esc & 0,000003 & $0,00001^{* * *}$ & 0,000001 & $0,0146^{* * *}$ \\
Esc_c & $0,0201^{* * *}$ & $0,0199^{* * *}$ & $0,0158^{* * *}$ & $-0,0115^{* * *}$ \\
Idade & $-0,0098^{* * *}$ & $-0,0141^{* * *}$ & $-0,0076^{* * *}$ & $0,0466^{* * *}$ \\
Est_c & $0,0445^{* * *}$ & $0,0414^{* * *}$ & $0,0459^{* * *}$ & $-0,0037$ \\
Cor & 0,0441 & 0,0816 & 0,1484 & 0,0267 \\
Urb & $-0,0097$ & $-0,0227$ & $-0,0286^{*}$ & 0,0145 \\
Comp & $0,0487^{* *}$ & $0,0377^{*}$ & 0,0078 \\
Filho & 0,0053 & $-0,00001$ & $0,0581^{* * *}$ & $0,1006^{* * *}$ \\
\hline Rend_c & 0,0402 & $0,121^{* * *}$ & 0,0037 & 0,0387 \\
Esc & & Estudo & $0,00001^{* * *}$ \\
Esc_c & $0,00002^{* * *}$ & $0,00001^{* * *}$ & $0,000005^{* *}$ & $-0,0104^{* *}$ \\
Idade & $-0,0262^{* * *}$ & $-0,0146^{* * *}$ & $-0,0069$ & $0,0139^{* * *}$ \\
Est_c & $0,0131^{* * *}$ & $0,0191^{* * *}$ & $0,012^{* * *}$ & $-0,0833^{* * *}$ \\
Cor & $-0,0852^{* * *}$ & $-0,0781^{* * *}$ & $-0,0842^{* * *}$ & $-0,1244$ \\
Urb & $-0,2612^{* *}$ & $-0,0635$ & $-0,5634^{* *}$ & 0,0283 \\
Comp & $0,0603^{* * *}$ & $-0,0074$ & $0,0481^{* *}$ & $-0,0065$ \\
& 0,0047 & $-0,0727^{* * *}$ & $-0,0151$ & $-0,015^{* *}$
\end{tabular}




\begin{tabular}{|c|c|c|c|c|}
\hline & 2011 & 2012 & 2013 & 2014 \\
\hline Filho & $-0,0826$ & $-0,2331^{* * *}$ & $-0,0812$ & $-0,2539^{* * *}$ \\
\hline \multicolumn{5}{|c|}{ Trabalho e estudo } \\
\hline Rend_c & $0,000008^{* * *}$ & $0,000009^{* * *}$ & $0,000002^{* *}$ & $0,000007^{* * *}$ \\
\hline Esc & $0,0188^{* * *}$ & $0,0136^{* * *}$ & $0,0138^{* * *}$ & $0,0151^{* * *}$ \\
\hline$E s c_{-} c$ & $-0,0016$ & $-0,0019$ & $-0,0023$ & $-0,0037^{* *}$ \\
\hline Idade & 0,0036 & $-0,0015$ & 0,002 & 0,0021 \\
\hline Est_c & $-0,0359$ & $-0,2529^{*}$ & 0,1284 & 0,0399 \\
\hline Cor & $-0,0418^{* * *}$ & $-0,0089$ & $-0,0157$ & $-0,00009$ \\
\hline Urb & $-0,0457^{* * *}$ & 0,0173 & $-0,0085$ & $0,0474^{* *}$ \\
\hline $\operatorname{Comp}$ & $-0,0013$ & $0,0106^{* *}$ & $-0,0043$ & 0,0023 \\
\hline Filho & $-0,0486$ & $-0,0657$ & $-0,124^{* * *}$ & $-0,065$ \\
\hline \multicolumn{5}{|c|}{ Nem-nem } \\
\hline Rend_c & $-0,00003^{s}$ & $-0,00003^{s}$ & $-0,000008^{s}$ & $-0,00003^{s}$ \\
\hline Esc & $-0,0126^{* * *}$ & $-0,0188^{* * *}$ & $-0,0227^{* * *}$ & $-0,0136^{* * *}$ \\
\hline$E s c \_c$ & 0,0016 & $-0,0031$ & $-0,0022$ & 0,0012 \\
\hline Idade & $-0,0371^{s}$ & $-0,0383^{s}$ & $-0,0363^{s}$ & $-0,0345^{s}$ \\
\hline Est_c & $-0,2530^{s}$ & $-0,2348^{s}$ & $-0,2866^{s}$ & 0,0882 \\
\hline Cor & $-0,0088$ & $0,039^{* *}$ & $-0,0038$ & $-0,0012$ \\
\hline Urb & $-0,0077$ & 0,0177 & $-0,0341$ & $-0,0554^{* * *}$ \\
\hline $\operatorname{Comp}$ & $-0,0016$ & 0,0057 & 0,0036 & 0,005 \\
\hline Filho & $-0,0910^{s}$ & $-0,1778^{s}$ & $-0,1664^{s}$ & $-0,2183^{s}$ \\
\hline
\end{tabular}

Fonte: Elaboração dos autores.

Nota: Valores sucedidos dos símbolos $\left({ }^{* *}\right),\left({ }^{* *}\right)$ e $\left({ }^{*}\right)$ indicam significância estatística a nível de $1 \%, 5 \%$ e $10 \%$ de confiabilidade respectivamente. Valores sucedidos de "s" indicam significância estatística a 5\% de confiabilidade e relevância de acordo com a literatura econômica.

Os resultados obtidos com a variável renda do chefe da família, nos anos em que essa obteve significância estatística, indicaram que acréscimos nessa variável elevam a probabilidade de as jovens do sexo feminino escolherem apenas trabalhar, apenas estudar ou trabalhar e estudar. Por outro lado, elevaçóes na renda do chefe da família reduzem a probabilidade de o indivíduo do sexo feminino possuir um perfil "nem-nem".

A variável escolaridade obteve resultados contrários aos encontrados nas estimaçóes feitas para o sexo masculino no que diz respeito às categorias trabalho e estudo. Verificase que, ao contrário dos homens, as mulheres com maior nível de escolaridade estáo mais propensas a escolherem o trabalho como decisão ocupacional e possuem menores probabilidades de optarem por apenas estudar, de forma que o sinal obtido na categoria foi encontrado também no estudo de Tillmann e Comin (2016) para as mulheres com níveis de escolaridade mais elevados.

Verificou-se, também, que a escolaridade do chefe da família interfere de forma negativa nas decisóes de escolha por trabalho das mulheres da regiáo Nordeste. Dessa forma, elevaçóes nessa variável reduzem a probabilidade de as jovens do sexo feminino optarem por apenas trabalhar. Por outro lado, o aumento na escolaridade do chefe do domicílio eleva a probabilidade de escolha das mulheres por apenas estudar. Em tese, chefes de famílias com maiores níveis de instrução repassam para os filhos a importância das obrigaçóes escolares, transmitindo essa característica aos seus descendentes. 
A partir das análises feitas para os coeficientes estatisticamente significantes da variável idade, verifica-se que mulheres mais velhas estão mais propensas a apenas trabalhar e a possuírem um perfil "nem-nem". Além disso, as jovens do sexo feminino com maior idade possuem menores probabilidades de dedicarem-se apenas ao estudo. Já em relaçáo às mulheres casadas, observa-se que essas estáo menos propensas a dedicarem-se exclusivamente ao estudo, e possuem maior probabilidade de pertencerem à geração "nemnem", assim como indicado por Tillmann e Comin (2016) em seu estudo voltado para o Brasil utilizando dados de 2011.

O fato de a mulher residir no meio urbano da região Nordeste eleva a probabilidade de escolha pelo trabalho. Nas demais categorias, verifica-se que o meio urbano contribuía negativamente na escolha por estudo, em 2012, por trabalho e estudo, nos anos de $2011 \mathrm{e}$ 2014 e por lazer, no ano de 2014.

Em relação à maternidade, observa-se que essa variável obteve significância estatística a 5\% de confiabilidade em dois dos quatro anos estudados nas duas primeiras categorias. Os resultados obtidos com os coeficientes significantes mostraram que o fato de a mulher ser mãe reduz a probabilidade de escolha apenas pelo estudo e pela conciliaçáo de trabalho e estudo. Além disso, as jovens do sexo feminino que são mães estão mais propensas a optarem por apenas trabalhar, além de apresentarem maiores chances de possuírem um perfil "nem-nem". Levando em consideração que o presente trabalho não considera os afazeres domésticos como forma de trabalho e considerando a perspectiva de Camarano et al. (2012), esse resultado pode ser justificado pelo fato de essas mulheres terem constituído família e estejam desempenhando o tradicional papel de mãe ou dona de casa.

Um comparativo das três estimaçóes feitas permite identificar que a implantação de medidas que favoreçam a obtenção de renda e a elevação dos níveis de escolaridade dos jovens da região Nordeste atua como fator redutor da quantidade de jovens "nemnem". Além disso, ressalta-se a perspectiva de Gonçalves e Monte (2008) e Vasconcelos et al. (2016) que demonstram a existência da necessidade de implantação de medidas que busquem a inserção dos jovens no mercado de trabalho.

\section{CONSIDERAÇÓES FINAIS}

O presente trabalho buscou identificar os fatores determinantes do perfil "nem-nem" dos jovens da região Nordeste do Brasil, além de indicar a probabilidade de cada possível escolha de ocupaçáo em relaçáo à amostra estudada, levando em consideração o sexo dos indivíduos. Para tanto, foram selecionados os indivíduos com idade entre 16 e 29 anos, residentes na região descrita utilizando dados da PNAD referente aos anos de 2011, 2012, 2013 e 2014. As análises foram feitas através da estimação de um modelo Probabilístico Multinomial que permitiu encontrar a probabilidade de escolha dos jovens da regiáo estudada para cada opçáo de escolha ocupacional.

De uma maneira geral, os resultados encontrados com o método utilizado apresentaram-se de acordo com os estudos existentes sobre o tema e reforçam as conclusóes tomadas em estudos feitos para outras amostras como em Camarano et al. (2012), Monteiro (2013) e Tillmann e Comin (2016). 
Os resultados demonstraram que incrementos na renda e na educação do chefe da família e na escolaridade dos indivíduos estudados atuam como fatores que elevam as probabilidades de escolha por atividades ligadas ao estudo na regiāo Nordeste, evidenciando que melhorias na qualidade educacional e o incremento de medidas voltadas para a geração de emprego e renda favorecem a permanência dos jovens na escola.

Além disso, constatou-se que indivíduos com maiores níveis de escolaridade, sejam eles do sexo masculino ou feminino estão menos propensos a permanecerem fora da escola e do mercado de trabalho. Nesse sentido, os resultados apontaram para a necessidade de implantação de medidas que possibilitem a permanência ou inserçáo dos jovens da regiấo Nordeste na escola.

Em relação aos jovens do sexo masculino, concluiu-se que a escolha por lazer dos indivíduos estudados está ligada à idade, ao meio urbano e à escolaridade do chefe da família. Já em relação aos indivíduos do sexo feminino, os resultados demonstraram que o perfil "nem-nem" está relacionado à idade, ao casamento e à maternidade.

Quando se trata de uma conjuntura com ambos os sexos, concluiu-se que filhos de pais com maiores níveis de instrução estáo menos propensos ao trabalho e mais propensos a optarem pelo estudo. Nesse caso, a escolha pelo ócio é dada pela idade, pelo casamento, pelo meio urbano e pelo fato do indivíduo ser do sexo feminino.

Destaca-se, portanto, a importância da educação como política de longo prazo para redução da quantidade de jovens "nem-nem" na região Nordeste. Ressalta-se também a necessidade de implantação de medidas que possibilitem a inserção dos jovens no mercado de trabalho na idade adequada.

Por fim, concluiu-se que a aplicação de políticas públicas voltadas para a inserção ou manutenção dos jovens da região Nordeste do Brasil no mercado de trabalho ou na escola deve considerar os diferentes efeitos surtidos em relação ao sexo do indivíduo. Além disso, é possível concluir que as mulheres demandam uma maior atenção em medidas que visem combater o comportamento “nem-nem” dos jovens da região Nordeste do Brasil.

Como o presente estudo é dedicado especificamente a região Nordeste do Brasil, sugere-se para pesquisas posteriores a verificação do problema aqui abordado para outras regiôes do país, o que possibilitaria um confronto de resultados e uma maior discussão para com as conclusões tomadas.

\section{REFERÊNCIAS}

ALEXANDRE, A. A. S; MENEZES-FILHO, N. A. O papel da oferta de trabalho no comportamento dos retornos à educação no Brasil. Pesquisa e Planejamento Econômico (PPE). v. 35, n.2, ago. 2005.

BECKER, G. A Theory of the allocation of time. The Economic Journal, v. 75, n. 299, p. 493-517, 1965. 
CACCIAMALI, M. C.; TATEI, F.; BATISTA, N. F. Impactos do Programa Bolsa Família Federal sobre o trabalho infantil e na frequência escolar. Revista de Economia Contemporânea, Rio de Janeiro, v. 14, n. 2, p. 269-301. 2010.

CAMARANO, A. A.; KANSO, S.; MELLO, J. L.; ANDRADE, A. Estão fazendo a transição dos jovens que não estudam, não trabalham e não procuram trabalho?. In: CAMARANO, Ana Amélia (Org.). Transiçáo para a vida adulta ou vida adulta em transição? Rio de Janeiro: IPEA, 2006.

. O que estão fazendo os jovens que não estudam, não trabalham e não procuram trabalho? Mercado de trabalho, v. 53, p. 37-44, 2012.

CARDOSO, A. Juventude, trabalho e desenvolvimento: elementos para uma agenda de investigação. Caderno CRH. Salvador, v. 26, n. 68, ago. 2013.

CARDOSO, E; SOUZA, A. "The Impact f Cash Transfers on Child Labor and School Attendence in Brazil". Working Paper, n. 04-W07. Department of Economics Vanderbilt University. 2004.

CIRÍACO, J. S; ANJOS JÚNIOR, O. R.; RODRIGUES, P. S.; ALVES, N. C. Geraçáo canguru? Fatores associados à permanência dos jovens cearenses no ambiente familiar de origem. In: XI ENCONTRO ECONOMIA DO CEARÁ EM DEBATE, 12. Anais... Fortaleza, 2015. IPECE, Fortaleza-Ce. 04 dez. 2015. Disponível em < http://www2.ipece. ce.gov.br/encontro/2015/trabalhos/Gera\%C3\%A7\%C3\%A3o\%20Canguru.pdf > . Acesso em: 29 de março de 2016.

CORSEUIL, C. H.; BOTELHO, R. U. (org.). Desafios à trajetória profissional dos jovens brasileiros. Rio de Janeiro: IPEA, 2014.

COSTA, J. S. M.; ULYSSEA, G. O fenômeno dos jovens nem-nem. In: CORSEUIL, C. H.; BOTELHO, R. U. (org.). Desafios à trajetória profissional dos jovens brasileiros. Brasília: IPEA, 2014.

FERREIRA, S. G. The provision of education and its impacts on college premium in Brazil. Revista Brasileira de Economia. v. 58, n. 2, 2004.

GARCIA, M. F.; ARAÚJO, E. C.; ARAÚJO, E. L.; FAUSTINO, I. A. A condição do jovem no mercado de trabalho brasileiro: uma análise comparativa entre o emprego e o primeiro emprego (1999-2009). Revista Economia. Brasília, v. 13, n. 3, p. 481-506, set./ dez. 2012.

GONÇALVES, M. F.; MONTE, P. A. Admissão por primeiro emprego e reemprego no mercado formal do Nordeste: um estudo mesorregional. In: Encontro Nacional de Estudos Populacionais, 6., 2008. Anais... Caxambu, 2008. Disponível em $<$ http://www. 
abep.nepo. unicamp.br/encontro2008/docspdf/abep2008_1313.pdf >. Acesso em 22 jan. 2015.

GONZAGA, G. et al. The effects of and apprenticeship program on labor market outcomes of youths in Brazil. In: MEETING OF THE BRAZILIAN ECONOMETRIC SOCIETY. 34. 2012. Anais... Porto de Galinhas, 2012.

GREENE, W. H. Econometric analysis. 6. ed. Nova Jersey: Pearson. 2008.

INSTITUTO NACIONAL DE GEOGRAFIA E ESTATÍSTICA, IBGE. Disponível em: <www.ibge.gov.br >. Acesso em: 20 de dezembro de 2016.

Pesquisa Nacional por Amostra de Domicílios, PNAD. Disponível em < http:// www.ibge.gov.br/home/estatistica/populacao/trabalhoerendimento/pnad2015/ microdados.shtm >. Acesso em: 05 jan. 2017.

KASSOUF, A. L. Aspectos socioeconômicos do trabalho infantil no Brasil. UNESCO. Ministério da Justiça, 2002.

MANCEBO, D; VALE, A. A; MARTINS, T. B. Políticas de expansão da educação superior no Brasil 1995-2010. Revista Brasileira de Educação. v. 20, n. 60, p.31-50, mar. 2015.

MENEZES FILHO, N. A.; CABANAS, P. H. F; KOMATSU, B. K. Crescimento da Renda e as Escolhas dos Jovens entre os Estudos e o Mercado de Trabalho. In: XLII ENCONTRO NACIONAL DE ECONOMIA, 52., Natal, 2014. Anais... Natal, 2014.

. (coord.). Adolescents in Latin America and Caribbean: examining time allocation decisions with cross-country micro data. Sáo Paulo: FIPE/USP, 2002.

MONTEIRO, J. Quem são os jovens nem-nem? Uma análise sobre os jovens que não estudam e não participam do mercado de trabalho. Texto de discussáo, FGV/ IBRE, $n$. 34, set. 2013.

REIS, M. C; CAMARGO, J. M. C. Educação e a participação dos jovens na força de trabalho. Pesquisa e Planejamento Econômico. São Paulo, v. 37, n. 2, p. 221-246, 2007.

ROBSON, K. Becoming NEET in Europe: a comparison of predictors and later- life outcomes. In: GLOBAL NETWORK ON INEQUALITY MINI-CONFERENCE, New York, 2008. Anais... New York, 2008.

SANTOS, A. L.; GIMENEZ, D. M. Inserção dos jovens no mercado de trabalho.

Estudos avançados, São Paulo, v. 29, n. 85, set./dez. 2015. 
SILVA, M. M. Geração à deriva: jovens nem-nem e a surperfluidade da força de trabalho no capital-imperialismo. Revista de Educaçáo Pública, Cuiabá, v. 25, n. 58, p. 119-136, jan./abr. 2016.

SIQUEIRA, L. B. O; LIMA, A. H. F. C; SILVA, M. V. B. Geração nem-nem e o efeito das aposentadorias e pensóes. In: XIII Encontro Nacional da Associação Brasileira de Estudos Regionais e Urbanos, 3., Curitiba, 2015. Anais... Curitiba, out. 2015.

SOBREIRA, D. B.; MORAIS, G. A. S.; SILVA, A. F.; COSTA, L. V. Desenvolvimento territorial, políticas públicas e sustentabilidade: novos olhares sobre o Nordeste rural. In: XI SOBER Nordeste, 11., Mossoró, 2016. Anais... Mossoró, nov. 2016.

TILLMANN, E; COMIN, F. Os determinantes da decisão entre estudo e trabalho dos jovens no Brasil e a geração nem-nem. Pesquisa e Planejamento Econômico, São Paulo, v. 46, n. 2, ago. 2016.

VASCONCELOS, A. M.; RIBEIRO, F. G.; GRIEBELER, M, C.; CARRARO, A. Geração "nem-nem": efeito do programa bolsa família? In: XLIV Encontro Nacional de Economia, 54., Foz do Iguaçu, 2016. Anais... Foz do Iguaçu, dez. 2016.

VIEIRA, C. S.; CABANAS, P.; MENEZES FILHO, N.; KOMATSU, B. K. Como as mudanças no trabalho e na renda dos pais afetam as escolhas entre estudo e trabalho dos jovens? Pesquisa e Planejamento Econômico, São Paulo, v. 46, n. 3, dez. 2016. 


\section{APÊNDICE:}

Tabela 5 - Estimação do modelo logit multinomial para ambos os sexos

\begin{tabular}{|c|c|c|c|c|}
\hline & 2011 & 2012 & 2013 & 2014 \\
\hline \multicolumn{5}{|c|}{ Trabalho } \\
\hline \multicolumn{5}{|l|}{ Constante } \\
\hline \multicolumn{5}{|l|}{ Renda_chefe } \\
\hline \multicolumn{5}{|l|}{ Escolaridade } \\
\hline \multicolumn{5}{|l|}{ Esc_chefe } \\
\hline Idade & \multicolumn{4}{|c|}{ Base outcome } \\
\hline \multicolumn{5}{|l|}{ Est_civil } \\
\hline \multicolumn{5}{|l|}{ Cor } \\
\hline \multicolumn{5}{|l|}{ Urbano } \\
\hline \multicolumn{5}{|l|}{ Componentes } \\
\hline \multicolumn{5}{|c|}{ Estudo } \\
\hline Constante & $10,3295^{* * *}$ & $4,1606^{* * *}$ & $10,0406^{* * *}$ & $10,1494^{* * *}$ \\
\hline Renda_chefe & $0,00004^{* * *}$ & 0,00001 & $0,00002^{* *}$ & $-0,000005$ \\
\hline Escolaridade & 0,0021 & 0,009 & $0,0323^{* *}$ & 0,0193 \\
\hline Esc_chefe & $0,0844^{* * *}$ & $0,109^{* * *}$ & $0,0812^{* * *}$ & $0,0882^{* * *}$ \\
\hline Idade & $-0,5253^{* * *}$ & $-0,5041^{* * *}$ & $-0,5018^{* * *}$ & $-0,517^{* * *}$ \\
\hline Est_civil & $-1,205^{* * *}$ & $-1,1819^{* * *}$ & $-2,4302^{* * *}$ & $-1,1671^{* * *}$ \\
\hline Cor & $0,2173^{* * *}$ & $0,1503^{* *}$ & 0,0694 & $0,2136^{* * *}$ \\
\hline Urbano & $0,3959^{* * *}$ & 0,1299 & 0,0987 & $0,2901^{* * *}$ \\
\hline Componentes & $-0,0465^{* *}$ & $-0,0736^{* * * *}$ & $-0,065^{* * *}$ & $-0,0654^{* * *}$ \\
\hline Sexo & $-1,113^{* * *}$ & $-0,96^{* * *}$ & $-1,0399^{* * *}$ & $-0,9488^{* * *}$ \\
\hline \multicolumn{5}{|c|}{ Trabalho e estudo } \\
\hline Constante & $4,4577^{* * *}$ & $4,1606^{* * *}$ & $4,4341^{* * *}$ & $4,0033^{* * *}$ \\
\hline Renda_chefe & $0,00005^{* * *}$ & $0,00002^{*}$ & $0,00002^{* * *}$ & $-0,000001$ \\
\hline Escolaridade & $0,0947^{* * *}$ & $0,0799^{* * *}$ & $0,0995^{* * *}$ & $0,0883^{* * *}$ \\
\hline Esc_chefe & $0,0342^{* * *}$ & $0,054^{* * *}$ & $0,0288^{* * *}$ & $0,0362^{* * *}$ \\
\hline Idade & $-0,2722^{* * *}$ & $-0,2746^{* * *}$ & $-0,2788^{* * *}$ & $-0,2727^{* * *}$ \\
\hline Est_civil & $-1,2055^{* *}$ & $-1,0001^{* *}$ & $-0,3537$ & 0,0682 \\
\hline Cor & $-0,0766$ & 0,0157 & $-0,1231$ & 0,1175 \\
\hline Urbano & $-0,3997^{* * *}$ & $-0,2285^{* * *}$ & $-0,2853^{* * *}$ & 0,0542 \\
\hline Componentes & $-0,0223$ & $0,0395^{*}$ & $-0,0125$ & 0,0054 \\
\hline Sexo & $-0,3492^{* * *}$ & $-0,389^{* * *}$ & $-0,388^{* * *}$ & $-0,3238^{* * *}$ \\
\hline \multicolumn{5}{|c|}{ Nem-nem } \\
\hline Constante & $2,2962^{* * *}$ & $1,9795^{* * *}$ & $2,6129^{* * *}$ & $2,405^{* * *}$ \\
\hline Renda_chefe & $-0,0001^{* * *}$ & $-0,0001^{* * *}$ & $-0,00008^{* * *}$ & $-0,0002^{* * *}$ \\
\hline Escolaridade & $-0,0733^{* * *}$ & $-0,1074^{* * *}$ & $-0,0861^{* * *}$ & $-0,0848^{* * *}$ \\
\hline Esc_chefe & $0,045^{* * *}$ & $0,0588^{* * *}$ & $0,0465^{* * *}$ & $0,0521^{* * *}$ \\
\hline Idade & $-0,0756^{* * *}$ & $-0,055^{* * *}$ & $-0,0736^{* * *}$ & $-0,0712^{* * *}$ \\
\hline Est_civil & 0,226 & $-0,0299$ & $-0,2869$ & 0,1924 \\
\hline Cor & 0,0282 & $0,1947^{* * *}$ & $-0,0811$ & 0,1616 \\
\hline Urbano & $0,322^{* * *}$ & $0,2174^{* * *}$ & 0,1078 & $0,2232^{* * *}$ \\
\hline Componentes & $-0,0295$ & 0,0096 & $-0,0415^{* *}$ & $-0,0025$ \\
\hline Sexo & $-0,9651^{* * *}$ & $-1,0779^{* * *}$ & $-0,8834^{* *}$ & $-0,8974^{* * *}$ \\
\hline
\end{tabular}

Fonte: Elaboração dos autores.

Nota: Valores sucedidos dos símbolos $\left({ }^{* * *}\right),\left({ }^{* *}\right)$ e $\left(^{*}\right)$ indicam significância estatística a nível de $1 \%, 5 \%$ e $10 \%$ de confiabilidade respectivamente. 
Tabela 6 - Estimaçấo do modelo logit multinomial para os jovens do sexo masculino

\begin{tabular}{|c|c|c|c|c|}
\hline & 2011 & 2012 & 2013 & 2014 \\
\hline \multicolumn{5}{|c|}{ Trabalho } \\
\hline \multicolumn{5}{|l|}{ Constante } \\
\hline \multicolumn{5}{|l|}{ Renda_chefe } \\
\hline \multicolumn{5}{|l|}{ Escolaridade } \\
\hline \multicolumn{5}{|l|}{ Esc_chefe } \\
\hline Idade & \multicolumn{4}{|c|}{ Base outcome } \\
\hline \multicolumn{5}{|l|}{ Est_civil } \\
\hline \multicolumn{5}{|l|}{ Cor } \\
\hline \multicolumn{5}{|l|}{ Urbano } \\
\hline \multicolumn{5}{|l|}{ Componentes } \\
\hline \multicolumn{5}{|c|}{ Estudo } \\
\hline Constante & $9,3674^{* * *}$ & $9,1383^{* * *}$ & $9,0621^{* * *}$ & $9,3495^{* * *}$ \\
\hline Renda_chefe & $0,00003^{*}$ & $-0,000001$ & $0,00004^{* * *}$ & 0,000004 \\
\hline Escolaridade & $0,0782^{* * *}$ & $0,0709^{* * *}$ & $0,0865^{* * *}$ & $0,0723^{* * *}$ \\
\hline Esc_chefe & $0,0877^{* * *}$ & $0,1007^{* * *}$ & $0,0869^{* * *}$ & $0,0856^{* * *}$ \\
\hline Idade & $-0,5766^{* * *}$ & $-0,5463^{* * *}$ & $-0,5337^{* * *}$ & $-0,5613^{* * *}$ \\
\hline Est_civil & $-0,8789$ & $-1,3933^{* *}$ & $-2,3247^{* *}$ & $-2,5924^{* *}$ \\
\hline Cor & $0,2145^{* *}$ & $0,2176^{* *}$ & $-0,0428$ & $0,2244^{* *}$ \\
\hline Urbano & $0,7917^{* * *}$ & $0,4965^{* * *}$ & $0,3041^{* * *}$ & $0,4973^{* * *}$ \\
\hline Componentes & $-0,0657^{* *}$ & $-0,0806^{* * *}$ & $-0,0921^{* * *}$ & $-0,0508$ \\
\hline \multicolumn{5}{|c|}{ Trabalho e estudo } \\
\hline Constante & $4,9411^{* * *}$ & $4,543^{* * *}$ & $4,464^{* * *}$ & $4,3032^{* * *}$ \\
\hline Renda_chefe & $0,00005^{* * *}$ & $0,00003^{* *}$ & $0,00004^{* * *}$ & 0,00000001 \\
\hline Escolaridade & $0,1174^{* * *}$ & $0,1116^{* * *}$ & $0,1285^{* * *}$ & $-0,1095^{* * *}$ \\
\hline Esc_chefe & $0,0327^{* * *}$ & $0,0555^{* * *}$ & $0,0315^{* *}$ & $0,0406^{* * *}$ \\
\hline Idade & $-0,3257^{* * *}$ & $-0,3232^{* * *}$ & $-0,3196^{* * *}$ & $-0,3168^{* * *}$ \\
\hline Est_civil & $-1,5431^{* *}$ & $-0,6029$ & $-0,512$ & 0,1012 \\
\hline Cor & 0,0102 & $-0,0025$ & $-0,2119^{*}$ & 0,1141 \\
\hline Urbano & $-0,3709^{* * *}$ & $-0,3509^{* * *}$ & $-0,3264^{* * *}$ & $-0,065$ \\
\hline Componentes & $-0,0194$ & 0,0346 & 0,0138 & 0,0301 \\
\hline \multicolumn{5}{|c|}{ Nem-nem } \\
\hline Constante & $0,8308^{* * *}$ & $0,6845^{* *}$ & $1,1354^{* * *}$ & $0,9382^{* * *}$ \\
\hline Renda_chefe & $-0,0001^{* * *}$ & $-0,00006^{* * *}$ & $-0,0001^{* * *}$ & $-0,0002^{* * *}$ \\
\hline Escolaridade & $-0,0624^{* * *}$ & $-0,104^{* * *}$ & $-0,0641^{* * *}$ & $-0,0665^{* * *}$ \\
\hline Esc_chefe & $0,0515^{* * *}$ & $0,0715^{* * *}$ & $0,0583^{* * *}$ & $0,0472^{* * *}$ \\
\hline Idade & $-0,0701^{* * *}$ & $-0,0569^{* * *}$ & $-0,0545^{* * *}$ & $-0,0576^{* * *}$ \\
\hline Est_civil & $-0,0455$ & $-0,8272^{* *}$ & $-1,0627^{* *}$ & $-0,0385$ \\
\hline Cor & 0,0402 & 0,1406 & $-0,1941^{* *}$ & 0,1237 \\
\hline Urbano & $0,652^{* * *}$ & $0,3645^{* * *}$ & $0,3624^{* * *}$ & $0,5284^{* * *}$ \\
\hline Componentes & $-0,0346$ & $-0,0013$ & $-0,0719^{* * *}$ & $-0,0107$ \\
\hline
\end{tabular}

Fonte: Elaboração dos autores.

Nota: Valores sucedidos dos símbolos $\left({ }^{* * *}\right),\left({ }^{* *}\right)$ e $\left(^{*}\right)$ indicam significância estatística a nível de $1 \%, 5 \%$ e $10 \%$ de confiabilidade respectivamente. 
Tabela 7 - Estimaçấo do modelo logit multinomial para os jovens do sexo feminiino

\begin{tabular}{|c|c|c|c|c|}
\hline & 2011 & 2012 & 2013 & 2014 \\
\hline \multicolumn{5}{|c|}{ Trabalho } \\
\hline \multicolumn{5}{|l|}{ Constante } \\
\hline \multicolumn{5}{|l|}{ Renda_chefe } \\
\hline \multicolumn{5}{|l|}{ Escolaridade } \\
\hline \multicolumn{5}{|l|}{ Esc_chefe } \\
\hline Idade & \multicolumn{4}{|c|}{ Base outcome } \\
\hline \multicolumn{5}{|l|}{ Est_civil } \\
\hline \multicolumn{5}{|l|}{ Cor } \\
\hline \multicolumn{5}{|l|}{ Urbano } \\
\hline \multicolumn{5}{|l|}{ Componentes } \\
\hline \multicolumn{5}{|c|}{ Estudo } \\
\hline Constante & $10,8489^{* * *}$ & $10,06^{* * *}$ & $10,6536^{* * *}$ & $10,3204^{* * *}$ \\
\hline Renda_chefe & $0,00007^{* * *}$ & $-0,00001$ & 0,00001 & $-0,000007$ \\
\hline Escolaridade & $-0,1684^{* * *}$ & $-0,1331^{* * *}$ & $-0,0978^{* * *}$ & $-0,0968^{* * *}$ \\
\hline Esc_chefe & $0,0831^{* * *}$ & $0,1211^{* * *}$ & $0,0702^{* * *}$ & $0,0918^{* * *}$ \\
\hline Idade & $-0,4481^{* * *}$ & $-0,424^{* * *}$ & $-0,4542^{* * *}$ & $-0,4466^{* * *}$ \\
\hline Est_civil & $-0,9369$ & $-0,5568$ & $-2,2425^{* *}$ & $-0,3261$ \\
\hline Cor & $0,2139^{*}$ & 0,0776 & $0,2713^{* *}$ & $0,2036^{*}$ \\
\hline Urbano & $-0,2173$ & $-0,3909^{* * *}$ & $-0,3324^{* *}$ & $-0,0853$ \\
\hline Componentes & $-0,0321$ & 0,05 & $-0,0266$ & $-0,0775$ \\
\hline Filho & $-0,4203^{*}$ & $-1,2544^{* * *}$ & $-0,4101$ & $-1,1687^{* * *}$ \\
\hline \multicolumn{5}{|c|}{ Trabalho e estudo } \\
\hline Constante & $3,6504^{* * *}$ & $3,2893^{* * *}$ & $4,3866^{* * *}$ & $3,3427^{* * *}$ \\
\hline Renda_chefe & $0,00006^{* * *}$ & 0,00001 & 0,00002 & $-0,000003$ \\
\hline Escolaridade & 0,0197 & $-0,0145$ & 0,0096 & 0,0236 \\
\hline Esc_chefe & $0,0367^{*}$ & $0,0517^{* * *}$ & 0,0235 & $0,0307^{* *}$ \\
\hline Idade & $-0,1886^{* * *}$ & $-0,1915^{* * *}$ & $-0,2171^{* * *}$ & $-0,2041^{* * *}$ \\
\hline Est_civil & $-0,4288$ & $-1,7299$ & 0,0872 & 0,2594 \\
\hline Cor & $-0,2095$ & 0,0524 & 0,0421 & 0,125 \\
\hline Urbano & $-0,5101^{* * *}$ & $-0,073$ & $-0,346^{* *}$ & 0,2207 \\
\hline Componentes & $-0,0329$ & 0,0573 & $-0,0469$ & $-0,0224$ \\
\hline Filho & $-0,4872^{*}$ & $-0,8911^{* * *}$ & $-0,9968^{* * *}$ & $-0,863^{* * *}$ \\
\hline \multicolumn{5}{|c|}{ Nem-nem } \\
\hline Constante & $3,6504^{* * *}$ & $2,4534^{* * *}$ & $4,0438^{* * *}$ & $3,5746^{* * *}$ \\
\hline Renda_chefe & $0,00006^{* * *}$ & $-0,0002^{* * *}$ & $-0,00003^{*}$ & $-0,0002^{* * *}$ \\
\hline Escolaridade & 0,0197 & $-0,1587^{* * *}$ & $-0,1634^{* * *}$ & $-0,1431^{* * *}$ \\
\hline Esc_chefe & $0,0367^{* *}$ & $0,0505^{* * *}$ & $0,0302^{* *}$ & $0,0582^{* * *}$ \\
\hline Idade & $-0,1886^{* * *}$ & $-0,0385^{* * *}$ & $-0,0959^{* * *}$ & $-0,0831^{* * *}$ \\
\hline Est_civil & $-0,4288$ & 0,5246 & 0,317 & 0,3588 \\
\hline Cor & $-0,2095$ & $0,2478^{* *}$ & 0,1296 & 0,1207 \\
\hline Urbano & $-0,5101^{* * *}$ & $-0,1001$ & $-0,4175^{* * *}$ & $-0,2821^{* *}$ \\
\hline Componentes & $-0,0329$ & 0,0215 & $-0,0055$ & $-0,0167$ \\
\hline Filho & $-0,4872^{*}$ & 0,1351 & $0,4219^{* *}$ & $0,3775^{* *}$ \\
\hline
\end{tabular}

Fonte: Elaboração dos autores.

Nota: Valores sucedidos dos símbolos $\left({ }^{* * *}\right),\left({ }^{* *}\right)$ e $\left(^{*}\right)$ indicam significância estatística a nível de $1 \%, 5 \%$ e $10 \%$ de confiabilidade respectivamente. 